Effects of I and use on trophic st ates and mil $\mathrm{t} i$ - $t$ axonom $\mathrm{c}$ di versi ty in Japanese farm ponds

\begin{tabular}{|l|l|}
\hline 著者 & $\begin{array}{l}\text { Usi o N si kawa, Nakagawa Megum, Aoki Takashi, } \\
\text { H guchi Shi nsuke, Kadono Yasur o, Akasaka } \\
\text { Minem t su, Takamur a Nor i ko }\end{array}$ \\
\hline 著者別表示 & 西川 潮, N si kawa Usi o \\
\hline $\begin{array}{l}\text { j our nal or } \\
\text { publ i cat i on ti t l e }\end{array}$ & Agr i cul t ur e, Ecosyst ens and Envi ronment \\
\hline vol une & 247 \\
\hline page range & $205-215$ \\
\hline year & $2017-09-01$ \\
\hline URL & ht t p: //doi . or g/10. 24517/00049679 \\
\hline
\end{tabular}




\section{Effects of land use on trophic states and multi-taxonomic diversity in Japanese}

\section{2 farm ponds}

4 Nisikawa Usio ${ }^{\mathrm{a}, *}$ Megumi Nakagawa ${ }^{\mathrm{b}}$, Takashi Aoki ${ }^{\mathrm{c}}$, Shinsuke Higuchi ${ }^{\mathrm{d}}$, Yasuro Kadono ${ }^{\mathrm{d}}$, $5 \quad$ Munemitsu Akasaka ${ }^{\mathrm{e}}$ and Noriko Takamura ${ }^{\mathrm{b}}$

6 a Institute of Nature and Environmental Technology, Kanazawa University, Kanazawa 920-1192, $7 \quad$ Japan

$8 \quad{ }^{b}$ Center for Environmental Biology and Ecosystem Studies, National Institute for Environmental 9 Studies, Tsukuba 305-8506, Japan

10 ' Suma-shofu High School, Kobe 654-0155, Japan (Present address: Fujimiga-oka 2-19-13, Nishi-ku, 11 Kobe 651-2214, Japan)

$12{ }^{d}$ Graduate School of Science, Kobe University, Kobe 657-8501, Japan

$13{ }^{e}$ Tokyo University of Agriculture and Technology, Tokyo 183-8509, Japan

$14 *$ Correspondence author at: Institute of Nature and Environmental Technology, Kanazawa 15 University, Kanazawa 920-1192, Japan

16 E-Mail: usio@,se.kanazawa-u.ac.jp (Nisikawa Usio) 
Farm ponds are among the most biodiverse anthropogenic freshwater habitats because of their small size, shallow water depth, and aquatic vegetation. Land-use changes, such as converting riparian

21 vegetation to human use or changing the management practices of farm ponds, are assumed to be major factors that change such ecosystems from a clear-water state to a turbid state, leading to deterioration of water quality and biodiversity in such ponds. Using the database of a large-scale pond survey, we evaluated the effects of surrounding land use (landscape factors and modern pond management practices), fish abundance, and other environmental variables on total phosphorus concentration and taxonomic richness patterns of six biological indicators associated with changes in the trophic state. Local- and landscape-level vegetation structure associated with land use and total fish abundance were among the factors influencing the total phosphorus concentration of farm ponds, a main driver of trophic state changes. In addition, a transition from a clear-water state to a turbid state was associated with lower taxonomic richness of aquatic plants, macroinvertebrates, and adult quality and biodiversity of farm ponds through maintenance of a clear-water state. Keywords: Biodiversity, Agricultural pond, Stable state, Alpha diversity, Satoyama

\section{Introduction}

Odonata, and a higher taxonomic richness of phytoplankton and fish. Based on these results, we discuss potential land-use and pond management strategies for conserving and/or restoring the water

er. Introduction

6 Land-use changes, such as conversion of natural vegetation to farmland or residential areas and changing traditional management practices of secondary nature, have bi-directional consequences for the environment and human society. On the one hand, some land-use practices, such as creation of farmland or urbanisation, are essential to meet the increasing demand for food and/or space for human society. On the other hand, such practices have detrimental impacts on biodiversity and ecosystem functions and thereby affect the ecosystem services upon which human society depends. It is widely acknowledged that solely conserving or restoring biodiversity and ecosystem services in protected areas is insufficient for sustainable conservation and use of natural resources (Lundholm and Richardson, 2010; Chester and Robson, 2013). For the purpose of reconciling biodiversity conservation and human use of natural resources, management of human-altered landscapes is important (Rosenzweig, 2003; Dudgeon et al., 2006). 
Despite the common view that anthropogenic ecosystems have low levels of biodiversity, recent studies have shown that water bodies in agricultural and urban landscapes, such as farm ponds, highway ponds, paddy fields, and irrigation ditches, play important roles in biodiversity conservation (Elphick, 2000; Cereghino et al., 2008; Le Viol et al., 2009; Negishi et al., 2014; Wezel et al., 2014). Farm ponds in particular have been shown to be among the most biodiverse water bodies because of their small size, shallow water depth, and aquatic vegetation (Williams et al., 2004; Davies et al., 2008). Developing strategies to manage the multiple functions of anthropogenic freshwater ecosystems beyond their roles of irrigating, cropping, or controlling storm water is a key challenge in conservation science.

In Japan, most natural floodplain wetlands in lowland areas have been converted into agricultural or urban areas. Although farm ponds are created primarily for irrigation purposes to meet the increasing demand for food, these ponds serve as refuge habitats for aquatic and semi-aquatic wildlife that once inhabited natural floodplain wetlands. In practice, farm ponds contain many indigenous or endangered species that are absent from natural wetland habitats (Takamura, 2012). However, biodiversity in farm ponds is threatened because of increased demands for land consolidation and changes in management styles of ponds over time.

Farm ponds have alternative stable states characterised by different trophic states: a clear-water state and a turbid state (Declerck et al., 2006; Phillips et al., 2016). Previous studies have reported that changes from a clear-water state to a turbid state in shallow lakes or ponds are caused by various abiotic and biotic stresses. For example, non-point source pollution from farmland and urban areas is a major factor that enhances nutrient input into shallow lentic systems (Carpenter et al., 1998). Land-use changes, such as deforestation in the surrounding area and input of agrochemicals through agricultural intensification, have been reported to deteriorate water quality and reduce the species richness of aquatic plants in farm ponds (Akasaka et al., 2010). Ecosystem engineering via bioturbation activities by fish or macrophyte cutting and destruction by non-native crayfish are among the major factors that cause macrophyte reduction (Rodriguez et al., 2005; Matsuzaki et al., 2007; Scheffer and van Nes, 2007). Furthermore, fish predation on zooplankton can have positive effects on phytoplankton via trophic cascades (Vanni et al., 1997). In most cases, such abiotic and biotic stresses are associated with trophic state changes via increased concentration of phosphorus and/or nitrogen (Jeppesen et al., 1997; Declerck et al., 2006) 
Although our understanding of how multi-taxonomic groups respond to eutrophication is growing

78 (Menetrey et al., 2005; De Marco et al., 2014; Rosset et al., 2014; Wezel et al., 2014), most researchers have directly addressed the response of biological indicators along the gradient of eutrophication and have not considered the relative effects of local and landscape factors on multitaxonomic diversity. Furthermore, studies reporting the relative effects of local and landscape stressors on farm pond biodiversity are often limited to a restricted set of taxonomic groups such as aquatic plants (Akasaka et al., 2010).

Using a database of 64 farm ponds with different land uses in western Japan (Takamura, 2011), we investigated the effects of surrounding landscape components, modern pond management practices, fish abundance, and other environmental variables on the trophic state of farm ponds to identify the major stressors of trophic state changes in such ponds. We hypothesised that local and landscape-level land uses, fish abundance, and the occurrence of invasive crayfish are significant stressors of trophic state changes. We subsequently documented the influence of changes in the trophic state on the taxonomic richness of phytoplankton, aquatic plants, zooplankton, macroinvertebrates, fish, and adult odonates in farm ponds. Given that aquatic plants provide refuge as well as foraging and/or spawning sites for many animals, and play vital roles in maintaining the clear-water state through various ecosystem functions (Jeppesen, 1998), we hypothesised that the taxonomic richness of aquatic plants and animals is positively associated with the clear-water state, while that of phytoplankton is negatively associated with such a state due to their counteracting association with aquatic plants (Phillips et al., 2016). However, we expect that responses of taxonomic groups along the gradient of trophic states may be weak when the effects of other local and landscape stressors are simultaneously considered.

\section{Methods}

\subsection{Study site}

$$
\text { We used a database of biota (phytoplankton, aquatic plants, zooplankton, benthic }
$$
macroinvertebrates, adult odonates, invasive animals, and floating-leaved macrophyte coverage), water quality, morphometric variables, landscape variables, and pond management at 64 farm ponds in the Kako River Basin of Hyogo Prefecture in western Japan (Takamura, 2011) (Figure 1, Table 1). Land- 
use variables consisted of both landscape variables (coverage of broadleaved forests, paddy fields, cropland, grassland, urban area, and freshwater within six multi-scale buffers ranging from $10 \mathrm{~m}$ to 2,000 $\mathrm{m}$ in radius) and modern pond management (coverage of concrete bank protection) (see below). Although the detailed history of each farm pond is unknown, most farm ponds in this region were created in the 19th century for the purposes of providing irrigation water to rice paddy fields.

We initially classified the farm ponds in the region on the basis of dominant land use (broadleaved forest, paddy fields, and urban area). For each land-use category, we subsequently selected three types of farm ponds on the basis of the aquatic vegetation characteristics (no vegetation, emergent macrophytes, and floating-leaved macrophytes). We arbitrarily selected seven to eight farm ponds from each of nine land use-aquatic vegetation categories. The 64 study ponds were generally small and shallow, with a mean surface area of 1.10 ha \pm 1.48 (SD) (range 0.08-11.43 ha) and mean maximum water depth of $1.7 \mathrm{~m} \pm 1.1(\mathrm{SD})$ (range $0.1-4.8 \mathrm{~m}$ ) (Table 1). The average total phosphorus concentration was $0.131 \mathrm{mg} \mathrm{L}^{-1} \pm 0.140$ (SD) (range $0.01-0.68 \mathrm{mg} \mathrm{L}^{-1}$ ), and the total nitrogen concentration was $1.32 \mathrm{mg} \mathrm{L}^{-1} \pm 1.30$ (SD) (range $0.20-5.61 \mathrm{mg} \mathrm{L}^{-1}$ ) in mid-summer (August).

\subsection{Pond surveys}

From April through November of 2006 and 2008, we sampled the farm ponds to assess water quality and taxonomic richness of phytoplankton, aquatic plants, zooplankton, macroinvertebrates, fish, and adult odonates. We used the six taxonomic groups as biological indicators because these groups are major components of farm pond communities and/or are generally taxon rich, and they are therefore suitable for bio-assessment based on taxonomic richness patterns. For phytoplankton, zooplankton, and water-quality samples, we performed a rapid assessment (without subsamples) at the 64 ponds over a relatively short period (7 days) in a single year to minimise temporal variation. For other biological indicators, we performed surveys over 2 or 3 years for logistical reasons. We also surveyed the occurrence (presence or absence) of two widely-distributed invasive species that can affect the water quality and taxonomic richness of biological indicators (see below). We performed a water-quality survey when nutrient concentrations would likely be highest (i.e. warmest month). For biological variables, we made sure to include the seasons when each taxonomic group would likely be at its highest abundance based on past experience with farm pond systems. 
134 From 23 to 29 August 2007, when cyanobacteria blooms were observed in some eutrophic farm 135 ponds, we measured the water transparency (Secchi depth) and concentrations of chlorophyll-a, total 136 phosphorus, total nitrogen, cyanobacteria, suspended solids, and bottom dissolved oxygen of each 137 pond. At each farm pond, we took one measurement or sample for each water quality variable. We 138 measured the concentration of cyanobacteria $20 \mathrm{~cm}$ below the water surface using a multiparameter 139 water-quality sonde (YSI6600; YSI, Yellow Spring, Ohio) and dissolved oxygen immediately above 140 the pond bottom using a dissolved oxygen meter (YSI58; YSI). By analysing a 2 L sample of surface 141 water collected from each pond, we determined in the laboratory the concentration of total phosphorus 142 by the ascorbic acid method (APHA, 1998), total nitrogen by the persulfate digestion method (APHA, 143 1998), suspended solids by drying $\left(103^{\circ} \mathrm{C}\right.$ for $\left.1 \mathrm{~h}\right)$ and combusting $\left(550^{\circ} \mathrm{C}\right.$ for $\left.1 \mathrm{~h}\right)$ duplicate filtered 144 subsamples, and chlorophyll-a using a spectrophotometric method after extraction in 99\% methanol 145 (Marker et al., 1980).

\subsubsection{Phytoplankton}

From 23 to 29 August 2007, we collected a water sample from $20 \mathrm{~cm}$ below the water surface of the 148 deepest part of each pond using a 100-mL plastic bottle. At each farm pond, we took one water149 phytoplankton sample. Following collection of each sample, we added several drops of Lugol's solution for sample preservation. In the laboratory, we used the sedimentation procedure (Utermöhl,

151 1958) to identify phytoplankton (mostly to the species level except for unidentifiable taxa) with the aid 152 of an inverted microscope $(400 \times)$. At each farm pond, we calculated total number of taxa as a measure 153 of the taxonomic richness of phytoplankton.

\subsubsection{Aquatic plants}

From August to September 2006 and 2007, we recorded the occurrence of free-floating macrophytes, floating-leaved macrophytes, emergent macrophytes, and submerged macrophytes 157 including charophytes in the study ponds while walking along the perimeter of the ponds. For deeper 158 parts, we took a floater or boat out onto ponds and raked or lobbed a grapnel (a rake-like device 159 mounted on a rope) on the pond bottom. Aquatic plants were identified mainly to the species level. At 
each farm pond, we calculated the total taxonomic richness of aquatic plants based on the one-time summer survey.

\subsubsection{Zooplankton}

From 23 to 29 August 2007, we used a plankton net (diameter $30 \mathrm{~cm}$, length $70 \mathrm{~cm}$, mesh size 25 $\mu \mathrm{m})$ to perform a vertical net sweep $10 \mathrm{~cm}$ above the pond bottom at the centre of each pond. At each farm pond, we took one zooplankton sample. Samples were preserved in $1 \%$ neutral buffered formalin (APHA, 1998) and transported to the laboratory for microscopic analyses. In the laboratory, we identified zooplankton with the aid of inverted and binocular microscopes (40-200×). We counted at least 100 individuals for Copepoda, Podocopida and Rotifer, respectively. The zooplankton samples were identified mainly to species level; when species identification was not possible, such samples were identified to next possible taxonomic level (genus, family, etc.). At each farm pond, we calculated the total taxonomic richness of zooplankton.

\subsubsection{Macroinvertebrates}

In May of 2006 and 2007, we performed 3-12 horizontal net sweeps of $50 \mathrm{~cm}$ using a D-framed net (width $30 \mathrm{~cm}$, length $30 \mathrm{~cm}$, mesh size $200 \mu \mathrm{m}$ ) in the vegetated areas of the pond perimeter. We performed stratified sampling with three subsamples taken from each of up to four habitat types. In addition, we collected three Ekman grab samples $(15 \times 15 \mathrm{~cm})$ from haphazardly selected points in the central area of each pond. We preserved the macroinvertebrate-sediment mixture in $10 \%$ formalin and transported the samples to an environmental consultant company (Chiiki Kankyo Keikaku, Takatsuki, Japan) for identification to the lowest possible taxonomic unit (mainly to the genus level). At each pond, we calculated macroinvertebrate taxonomic richness using combined data from the sweep and Ekman grab samples.

\subsubsection{Fish and invasive species}

From August to September 2006 and 2007, we sampled fish and decapod crustaceans by setting two fixed fishing nets (width $600 \mathrm{~cm}$, length $304 \mathrm{~cm}$, openings $69 \mathrm{~cm}$, mesh size $4 \mathrm{~cm}$ ) overnight along the perimeter of each pond and five baited (dried squid and fish sausages) box-shaped minnow traps $(25 \times$ $25 \mathrm{~cm}$, length $40 \mathrm{~cm}$, openings $6 \mathrm{~cm}$, mesh size $2 \mathrm{~mm}$ ) overnight at points equally spaced along the 
long axis of each pond. The following morning, we identified the animals in the nets and traps. We captured fish, decapod crustaceans, amphibians, and reptiles. In the present paper, however, we consider the data only for fish and the red swamp crayfish (Procambarus clarkii). We did not include amphibians in the analyses because no indigenous amphibian species were captured, probably because the survey was not performed when most indigenous amphibians spawn (early spring). We also excluded reptiles (turtles) from the analyses because the only indigenous turtle species (Mauremys japonica) was rare (occurred in only 4 of 64 sites) in the study ponds. At each farm pond, we calculated the total taxonomic richness and abundance (catch per unit effort) of fish using combined data from the fixed-net fishing and trapping.

$$
\text { Bluegill (Lepomis macrochirus) and red swamp crayfish were widely distributed non-native }
$$
invasive species in the study area (Usio et al., 2009). We determined the presence or absence of bluegill and red swamp crayfish using data from the fixed-net fishing, trapping, dip netting, and Ekman grab sampling.

\subsubsection{Adult odonates}

At each pond, we surveyed adult odonates between April and November (with the exception of August) of 2006 and 2008, for a total of six times. On average, we surveyed each pond for $22 \min ( \pm$ $14 \mathrm{SD}$ ) while walking the accessible parts of the pond perimeter or paddling along the pond margin. To avoid misidentification, we recorded sighted adult odonates using a video camera (DCR-HC96, SONY Inc., Japan). We identified most adult dragonflies to the species level by sight and later confirmed using the video recordings. For damselflies and Gomphidae, we identified individuals from samples collected using a sweep net or from the video recordings. In the subsequent statistical model, we used the total number of adult odonate species found at each farm pond during the six surveys.

\subsection{Landscape variables}

For each farm pond, we used ArcGIS version 9.1 (ESRI, Redlands, California) to calculate the coverage (proportions) of broadleaved forests, paddy fields, cropland, grassland, urban area, and freshwater within six multi-scale buffers ranging from $10 \mathrm{~m}$ to 2,000 $\mathrm{m}$ in radius (i.e. 10, 100, 250, $500,1000,2000 \mathrm{~m})$. We created buffers from the edge of each farm pond that had a shape identical to that of the pond. Within these buffers, we calculated the coverage of each landscape factor using a 
215 land-use map (scale: 1:25,000) of the Japan Integrated Biodiversity Information System (Ministry of 216 the Environment, 2000).

\section{2.4. Pond management}

218 Concrete bank construction is a typical, modern pond management practice in Japanese farm ponds 219 that is implemented to avoid bank erosion and save labour for grass mowing. Using city planning maps 220 (scale: 1:2,500) and ArcGIS, we calculated the proportion of concrete bank construction at each farm 221 pond.

222 In contrast, pond draining is a traditional pond management practice that is performed to improve 223 water quality or conduct social events, such as fish catching and barbequing. Through telephone 224 interviews or direct communication with pond managers, we asked whether farm ponds had been 225 drained prior to our field survey. Based on the interviews, we categorised ponds as drained (showing 226 cracked earth at the bottom), partially drained (retaining water throughout the draining season), or 227 undrained. We also asked the pond managers to provide the main water source for farm ponds. We 228 categorised the source of water as agricultural drainage, dam water, or natural water (creek, 229 underground, and/or rain water).

\subsection{Data analysis}

We used principal component analysis (PCA) on correlation matrices to reduce the seven highly correlated water-quality variables (chlorophyll-a, total phosphorus, total nitrogen, cyanobacteria, suspended solids, bottom dissolved oxygen, and Secchi depth) to produce reduced sets of orthogonal variables. All data were either log- or fourth-root transformed and subsequently standardised before being used in the analysis. We retained the first and second principal component axes that accounted 236 for 73.8 and $15.2 \%$ of the variance in water quality, respectively (Table S1). The positive loading of 237 the first principal component axis (Water PC1) was represented by chlorophyll-a (0.416), total 238 phosphorus $(0.411)$, total nitrogen $(0.404)$, cyanobacteria $(0.411)$, and suspended solids $(0.410)$, while 239 the negative loading was represented by Secchi depth $(-0.394)$. The positive loading of the second 240 principal component axis (Water PC2) was represented by bottom dissolved oxygen (0.945). Water 241 PC1 and Water PC2 were subsequently used as predictors in boosted regression-tree (BRT) models 242 (see below). 
When modelling water quality as the response variable, we used the total phosphorus concentration as a major driver of eutrophication and algal blooms in farm ponds. Although some studies have shown evidence of nitrogen limitation in lentic systems (Dolman et al., 2012), the concentrations of total phosphorus and total nitrogen were likewise highly correlated with chlorophyll-a $(r>0.90)$.

The importance of landscape variables on farmland biodiversity depends on the spatial scale (Raebel et al., 2012; Usio et al., 2015). Therefore, we used generalised linear models with either Gaussian (identity link) or Poisson distributions (log link) to analyse each of six spatial scales separately in terms of how taxonomic richness of phytoplankton, aquatic plants, zooplankton, macroinvertebrates, fish, and adult odonates responded to the surrounding landscape variables. We selected the best spatial scale on the basis of the lowest Akaike Information Criterion (AIC) (Burnham and Anderson, 2002). We considered only one spatial scale for each biological indicator in further analyses. When none of the spatial scales showed sufficient explanatory power relative to the null model $(\Delta \mathrm{AIC}<2)$, we did not include landscape variables as explanatory variables in further analyses.

We used BRT models to investigate the effects of land-use variables (i.e. landscape variables and modern pond management) and fish abundance on the total phosphorus concentration relative to other environmental variables. The BRT approach combines a statistical model (i.e. regression tree model) and machine learning techniques (i.e. boosting), such that boosting is used for adaptively combining large numbers of relatively simple tree models to optimise predictive performance (Elith et al., 2008).

261 We used BRT models because they allow complex or irregular relationships between predictors and responses, which are common in field data (Elith et al., 2008). Prior to the analyses, we checked for collinearity among predictors $(r>0.70)$. Consequently, we removed elevation and the proportion of urban areas, because both variables were highly correlated with the proportions of broadleaved forests, grassland, freshwater, and/or concrete bank construction at many spatial scales. We treated the response variable as having a Gaussian distribution following log transformation. We assessed the relative importance of land-use variables and fish abundance in the following three ways: their frequencies of selection in the BRT model, their partial dependence plots, and their effects on the explained deviance $\left(1-\right.$ residual deviance / null deviance]) expressed as percentages $\left(D^{2}\right)$. We assessed the effects of each land-use variable (at the best spatial scale) and fish abundance on the explained deviance by comparing the explained deviance in the model excluding the land-use variable or fish abundance from predictors to that of the full model. After initial inspections, we implemented 
BRT models with a tree complexity of 2 and a bagging fraction of 0.5 with 10 -fold cross-validation. A

274 learning rate was set to ensure that at least 1,000 trees were produced during the fitting process (Elith 275 et al., 2008). We performed the BRT modelling in the gbm library (Ridgeway, 2016) in R version 276 3.3.2 (R Development Core Team, 2016) with an additional R code written by Elith et al. (Elith et al., 277 2008).

278 To investigate the influence of changes in the trophic state on taxonomic richness patterns of farm 279 pond communities, we subsequently constructed six BRT models using taxonomic richness of 280 biological indicators as response variables. We defined the clear-water and turbid states as alternative 281 trophic phases along the gradient of Water PC1, where positive loading was represented by 282 eutrophication-related variables, such as chlorophyll-a, total phosphorus, total nitrogen, cyanobacteria, 283 and suspended solids (i.e. turbid state), and negative loading was represented by water transparency 284 (i.e. clear-water state). We assessed the influence of Water PC1 on the taxonomic richness of 285 biological indicators relative to management and other environmental variables. We treated each 286 response variable as having either a Gaussian or Poisson distribution with a tree complexity of 2 and a 287 bagging fraction of 0.5 with 10 -fold cross-validation. We assessed the relative importance of water 288 PC1 in three ways using the procedure described above.

289 In all BRT models, we inspected whether a spatial autocorrelation existed in the residuals of the 290 BRT models using semi-variograms (ncf package; Bjornstad, 2016) and Moran’s I statistics (spdep 291 package; Bivand, 2016). When the residual of a BRT model appeared to be spatially autocorrelated 292 (Moran's I: $P<0.05$ ), we calculated the residual autocovariate (RAC) (Crase et al., 2012). We applied 293 the inverse distance-weighting scheme to calculate RAC (Dormann et al., 2007).

\section{3. Results}

\subsection{Farm pond communities}

The total number of taxonomic groups identified from the 64 ponds were 336 for phytoplankton, 70

297 for aquatic plants (excluding 6 non-native species), 132 for zooplankton, 162 for macroinvertebrates 298 (excluding 5 non-native species), 11 for fish (excluding 6 non-native species), and 59 for adult 299 Odonata. The median taxonomic richness of aquatic plants (3.5) and fish (1.0) were relatively low, 
300 while those of phytoplankton (39.0), zooplankton (21.0), macroinvertebrates (20.0), and adult Odonata 301 (14.0) were relatively high (Figure 2).

302 For fish, the native stone moroko (Pseudorasbora parva (Cyprinidae)) and the invasive bluegill 303 (Lepomis macrochirus (Centrarchidae) dominated the fish assemblages in terms of mean abundance 304 (Pseudorasbora: 49.7\%; Lepomis: 49.1\%) and prevalence (Pseudorasbora: 37.5\%; Lepomis: 60.9\%).

305 3.2. Scale-dependent effects of landscape variables on the total phosphorus concentration and 306 taxonomic richness of farm pond communities

307 The total phosphorus concentration and taxonomic richness of most farm pond communities were at 308 least in part influenced by landscape variables (Table 2). The most relevant spatial scales differed 309 among chemical or biological indicators. Phytoplankton richness (10 and $100 \mathrm{~m})$, zooplankton richness 310 (250 and $500 \mathrm{~m})$, and adult Odonata richness $(500 \mathrm{~m})$ were most associated with landscape variables at 311 relatively short-distance spatial scales, while total phosphorus concentration $(2,000 \mathrm{~m})$ and 312 macroinvertebrate richness $(1,000$ and 2,000 m) were most associated with relatively distant spatial 313 scales. Fish richness (10 and 1,000 m) showed associations with multiple spatial scales at short and 314 distant scales. Aquatic plant richness was associated with landscape variables at a 2,000 m scale.

315 However, the AIC value of landscape variables at the 2,000 $\mathrm{m}$ scale showed little difference relative to 316 that of the null model $(\Delta \mathrm{AIC}<2)$, indicating that the landscape variables were not significant 317 predictors of aquatic plant richness.

318 3.3. Effects of land use and other environmental variables on total phosphorus concentration

319 A BRT model for total phosphorus concentration incorporating the best spatial scale of landscape 320 variables (i.e. 2,000 m radius) showed that a high concentration of total phosphorus was associated 321 with shallow water, a low proportion of broadleaved forest areas, a low proportion of grassland areas, a 322 high proportion of paddy field areas, a high proportion of concrete bank construction, high fish 323 abundance, a low proportion of floating-leaved macrophyte coverage, and ponds that use agricultural 324 drainage as the main water source (Figure 3). Among eight predictors that showed significant 325 contributions in explaining total phosphorus concentration, the relative percentage contributions of 326 
$20.6 \%$ ), and explained deviance changed from $-1.2 \%$ to $0.9 \%$ when each land-use variable was

328 excluded from the simplified model (Table 3).

329 Among the four land-use variables, the proportion of broadleaved forest areas had the largest 330 contribution in terms of percentage contribution (20.6\%). Fish abundance was also a significant 331 predictor of the total phosphorus concentration of the farm ponds. The percentage contribution of fish 332 abundance $(7.1 \%)$ was lower than that of the four land-use variables, although the change in explained 333 deviance $(1.5 \%)$ when the term was excluded from the simplified model was higher than that for any 334 of the land-use variables.

\subsection{Effects of clear-water and turbid states on taxonomic richness of farm pond communities}

BRT models for taxonomic richness of biological indicators incorporating the best spatial scales of

337 landscape variables showed that high taxonomic richness of aquatic plants, macroinvertebrates, and 338 adult Odonata were associated with a clear-water state while those of phytoplankton and fish were 339 associated with a turbid state (Figure 4, Table 4). For zooplankton, Water PC1 was not retained in the 340 simplified model. For the five taxonomic groups that showed significant associations with trophic 341 states, relative percentage contributions of Water PC1 were moderate (9.0-19.5\%), and explained 342 deviance changed from -0.6 to $1.6 \%$ when Water PC1 was excluded from the simplified models 343 (Table 4). Therefore, changes in trophic states lead to changes in the taxonomic richness of farm pond 344 communities.

\section{Discussion}

Our study of 64 farm ponds in western Japan showed that both land use and fish abundance were significant predictors of changes in the trophic state of ponds and that such changes are reflected in the

348 taxonomic richness patterns of farm pond communities. In subsequent sections, we discuss the 349 landscape responses of total phosphorus and the taxonomic richness of farm pond communities, effects 350 of land use and fish abundance on the total phosphorus concentration of farm ponds, effects of changes 351 in the trophic state on the patterns of taxonomic richness of farm pond communities, and management 352 strategies for farm ponds with regard to trophic states and biodiversity. 
The total phosphorus concentration, a main driver of changes in the trophic state, and the taxonomic richness of six biological indicators were associated with landscape variables from no distance (aquatic plants) to relatively short distance (phytoplankton: 10 and $100 \mathrm{~m}$; zooplankton: 250 and 500 m; adult Odonata: $500 \mathrm{~m}$ ), through to long-distance scales (total phosphorus: 2,000 m; macroinvertebrates: 1,000 and 2,000 m). In contrast, the taxonomic richness of fish was associated with both short- and distant-spatial scales (10 and 1,000 m). Researchers have indicated that the occurrence of specific species is generally associated with landscape factors depending on their ecological characteristics, such as life stages or growth forms (Akasaka et al., 2010; Raebel et al., 2012; Usio et al., 2014). For example, Raebel et al. (2012) showed that dragonflies were associated with landscape factors at long363 distance scales, while damselflies were associated with short-distance scales. A possible reason that 364 fish richness was associated with both short- and long-distance scales is that the occurrences of certain species were associated with different spatial scales depending on their dispersal abilities.

\subsection{Relative effects of land use and fish abundance on the total phosphorus concentration of farm} ponds forest and grassland at a 2,000-m radius, high coverage of paddy fields at a 2,000-m radius, and a high proportion of concrete bank construction. Furthermore, the total phosphorus concentration of farm ponds was also associated with shallow water depth, high fish abundance, low coverage of floatingleaved macrophytes, and farm ponds that used agricultural drainage as the main water source. Thus, land use, fish abundance, and other environmental variables were all important in determining the trophic states of farm ponds. As evident from the change in percentage deviance after excluding the variable from the simplified model, fish abundance had as influential an effect on trophic states as did the land-use variables.

We suspect that feeding activities by the stone moroko and bluegill, which dominate farm pond fish assemblages, had significant effects on the trophic state of farm ponds. Japanese cyprinid fishes are generally omnivores that feed on macroinvertebrates, periphyton, sediments, and zooplankton

380 (Kawanabe et al., 1989). Bluegill are also omnivores that feed on macrophytes, zooplankton, and 381 macroinvertebrates (Uchii et al., 2007). Bioturbation activities of fish through benthic feeding may 382 enhance the nutrient concentration via sediment resuspension and excretion (Matsuzaki et al., 2007). 
In contrast, surrounding vegetation coverage seemed to act as a buffer for eutrophication and sedimentation by suppressing surface run-off through evapotranspiration and filtering the nutrients in the water (Bosch and Hewlett, 1982). In addition, when correlation analyses were performed among landscape variables at a 2,000-m radius, the coverage of broadleaved forest showed a strong, negative correlation with the coverage of urban areas $(r=-0.78)$. Likewise, the coverage of grassland at a 2,000-m radius showed a moderately high correlation with the coverage of urban areas $(r=-0.66)$. Therefore, low coverages of broadleaved forest and grassland are indicators of urbanisation. Urban areas and paddy fields function as sources for non-point pollution (Carpenter et al., 1998). Surface runoff containing rich nutrients from urban and agricultural areas may result in loss of macrophytes, which in turn leads to a turbid state.

Macrophytes play key roles in maintaining a clear water state in shallow lentic systems through various ecological functions, including absorbing nutrients from the water column, suppressing sediment resuspension, releasing nitrogen in the atmosphere through denitrification, releasing allelochemicals, and providing refuge habitats for zooplankton grazers and thereby indirectly suppressing phytoplankton through a trophic cascade (Jeppesen, 1998). However, farm ponds with a high proportion of concrete bank construction may result in the loss of shallow coastal areas (ecotones), crucial habitats for macrophytes because of the high light availability. Likewise, Casas et al., (2011) reported that concrete ponds have high slope angles at their margins and are therefore associated with depauperate marginal vegetation although we have no direct evidence to test this hypothesis. We found a negative relationship between aquatic plant richness and concrete bank construction (Figure S1) and a positive relationship between the total phosphorus concentration and concrete bank construction (Figure 3). Furthermore, farm ponds with high phosphorus concentration were also associated with extremely low coverage of floating-leaved macrophytes (Figure 3).

Therefore, concrete bank construction had a positive association with a high total phosphorus concentration, at least in part through loss of macrophytes and their associated ecological functions. 
412 richness of phytoplankton and fish. Among the biological indicators that showed associations with

413 trophic states, clear-water or turbid states had the greatest impact on the taxonomic richness of

414 macroinvertebrates and phytoplankton, as indicated by the percentage change in deviance after Water

415 PC1 was excluded from the respective simplified models. Although live macrophytes contain chemical 416 compounds that deter direct grazing of aquatic animals, herbivorous-detritivorous macroinvertebrates 417 can utilise decayed plant tissue, trapped sediments, and periphyton in macrophytes as food sources.

418 Furthermore, the structural complexity of macrophytes is important in terms of providing refuge sites 419 for macroinvertebrates, including predatory taxa (Taniguchi et al., 2003; Kovalenko et al., 2012). In 420 addition, many dragonflies and damselflies rely on macrophytes as spawning, resting, and hatching 421 sites (Corbet, 1999; Butler and deMaynadier, 2008). Therefore, macrophytes play important roles as 422 indicators of a clear-water state, as well as autogenic ecosystem engineers.

\subsection{Implications for farm pond management}

Our results have important implications for conservation and restoration of farm ponds. First, coverage of broadleaved forest and grassland were among the significant variables that affected the trophic states of farm ponds. In terms of designating conservation areas, farm ponds surrounded by rich broadleaved forest and grassland at a 2,000-m radius from the ponds may be set as high-priority conservation areas because such ponds likely show a clear-water state represented by the presence of diverse aquatic plants, adult Odonata, and macroinvertebrates. The information on surrounding land use may also be used when creating a new pond; pond creation with the aim of restoring degraded

431 biodiversity in the area may be successful in a location surrounded by grassland and/or broadleaved 432 forest. However, caution is needed when selecting pond conservation or restoration sites in relation to vegetation structure because the influence of landscape factors is scale dependent, as shown in this and 434 past studies (Akasaka et al., 2010; Raebel et al., 2012).

In Europe, conservation of a clear-water state and high vegetation complexity in both existing and newly created farm ponds has been suggested as important in landscapes dominated by cropland, 437 provided that the farmland is extensively managed (Declerck et al., 2006). However, this may not apply in paddy-dominated landscapes in Japan, in which each paddy field is generally small $(<1$ ha),

439 extensively managed paddy fields are sporadically distributed, and paddy fields are generally 440 intensively managed at the regional level. Recently, increased attention has been paid to 
environmentally friendly farming (Usio, 2014). The main reason to implement environmentally

friendly farming is to develop multiple functions of farmland beyond their role of producing food (i.e. multi-functionality of agriculture). For this purpose, various environmentally farming practices have 444 been implemented, including wildlife-friendly farming (Usio, 2014). Halving or omitting the use of agrochemicals is the base procedure for all environmentally friendly farming practices. Conservation or restoration of farm ponds within paddy-dominated landscapes may become successful if the arrangement and size of environmentally friendly paddy fields are appropriately considered. For example, environmentally friendly farming may be implemented in a block rather than individually along the area connected by a single agricultural drainage system. In this way, the release of nutrientrich effluent from paddy fields to agricultural drainage may be mitigated more efficiently.

Pond management also plays a key role in determining the trophic states of farm ponds, because management practices affect the water quality of such ponds (Bonachela et al., 2013). In the past few decades, management styles of farm ponds have changed to minimise labour. In recent decades, concrete bank construction has been commonly employed to facilitate pond maintenance by avoiding erosion of banks. Whenever possible, concrete bank construction should be avoided to maintain farm ponds in a clear-water state. When it is unavoidable, care should be taken to maintain or create ecotones to facilitate macrophyte growth. In contrast, pond draining was commonly performed after rice harvest to catch fish as a social event until about the 1960s. Such fish catches were not only important as social events to facilitate mingling with other residents in the village but probably also important as "biomanipulation" through the removal of cyprinid fish. In recent decades, pond draining is no longer practised in most locations in the study region, due to aging and depopulated regional communities (Takamura, 2012). Even if pond draining has taken place, the practice is often not followed by a fish catch. A previous study reported that pond draining per se had little effect on the water quality of farm ponds (Usio et al., 2013). However, revitalisation of pond draining combined with fish catches may have the potential to maintain a clear-water state of farm ponds, provided that fish immigration from water sources is managed appropriately. Nevertheless, caution is needed when performing fish catches in a region invaded by the red swamp crayfish, as pond draining followed by fish-catches (or fish eradication) may facilitate invasion by this non-native crayfish species (Usio et al., 2009; Usio et al., 2013). In such regions, the crayfish should be concurrently managed, possibly 
through mechanical crayfish removal together with the conservation of carnivorous fish predators (e.g. Japanese eel Anguilla japonica, Japanese common catfish Silurus asotus) and their habitats.

Limitations of our study include its scope and analyses. In Japan, pond managers are generally concerned about the water quality of farm ponds, because pond water is used primarily for irrigated farming. Specifically, more than $54 \%$ of all farmland area in Japan comprises rice paddy fields (e-Stat, 2017). In rice farming, water quality, together with soil type and diurnal temperature variation, is of primary importance in determining rice grain quality and yield (Hirai et al., 2010). Given that a major focus of farm pond management in Japan is to maintain good water quality, biodiversity patterns in Japanese farm ponds are presumably determined primarily by water quality. Nevertheless, we incorporated water-quality and water management variables to a limited degree in the analyses. Furthermore, the primary focus of agro-ecosystem management is to enhance or secure crop productivity. Therefore, crop productivity may also be a significant determinant of biodiversity patterns in farm ponds. In regions where agricultural drainage is used as a main water source for farm ponds and/or where upper areas are intensively managed as farmland, crop productivity may also influence water quality due to the amount of fertilisers used on farmland. Future studies should encompass productivity indicators together with various water-quality indicators, farming practices, and water management toward a comprehensive understanding of the biodiversity patterns in farm ponds.

\section{Conclusions}

In summary, our findings show that land-use effects and fish abundance are major stressors leading to changes in trophic state and that the taxonomic richness of phytoplankton, aquatic plants, macroinvertebrates, fish, and adult Odonata change along the gradient of trophic states, but with the differential strength of such effects being relative to other local and landscape factors (Figure 5). Identifying the ecological thresholds of changes in the trophic states and multi-taxonomic diversity responses may be crucial for the design of plans for restoration of degraded farm ponds.

\section{Acknowledgments}

NU analysed the data and wrote the paper. MN performed the field studies, water-quality analyses, and identification of zooplankton and phytoplankton. TA performed the odonate surveys. SH and YK 
conducted the aquatic plant surveys. MA performed the land-use analyses. NT conducted the field studies and designed and supervised the study.

We thank I. Murakami, R. Ueno, and A. Ohtaka for macroinvertebrate identification, T. Murakami

and Y. Daihu for assistance with the field studies, M. Imada for assistance with the interviews of pond managers, Y. Oikawa and A. Saji for assistance with the laboratory studies, and anonymous reviewers for providing insightful comments on an early draft of the manuscript. We also thank the pond managers for granting permission to study at the farm ponds. The Environmental Research and Technology Development Fund (S9) of the Ministry of the Environment, Japan (2011-2015), supported the publication of this study.

\section{Reference}

APHA, Standard Methods for the Examination of the Water and Wastewater, 1998, American Public Health Association, Washington, DC, USA.

Akasaka, M., Takamura, N., Mitsuhashi, H., Kadono, Y., Effects of land use on aquatic macrophyte diversity and water quality of ponds. Freshwater Biol. 55, 2010, 909-922.

Bivand, R., spdep: Spatial dependence: weighting schemes, statistics and models, 2016, R package Version 0.6-8.

Bjørnstad, O.N., ncf: Spatial nonparametric covariance functions, 2016, R package Version 1.1-6.

Bonachela, S., Juan, M., Casas, J.J., Fuentes-Rodríguez, F., Gallego, I., Elorrieta, M.A., Pond management and water quality for drip irrigation in Mediterranean intensive horticultural systems. Irrig. Sci. 31, 2013, 769-780.

Bosch, J.M., Hewlett, J.D., A review of catchment experiments to determine the effect of vegetation changes on water yield and evapotranspiration. J. Hydrol. 55, 1982, 3-23.

Burnham, K.P., Anderson, D.R., Model Selection and Multimodel Interference: a Practical Information-theoretic Approach, 2002, Springer, New York, NY, USA.

Butler, R.G., deMaynadier, P.G., The significance of littoral and shoreline habitat integrity to the conservation of lacustrine damselflies (Odonata). J. Insect Conserv. 12, 2008, 23-36.

Carpenter, S.R., Caraco, N.F., Correll, D.L., Howarth, R.W., Sharpley, A.N., Smith, V.H., Nonpoint pollution of surface waters with phosphorus and nitrogen. Ecol. Appl. 8, 1998, 559-568. 
Casas, J., Toja, J., Bonachela, S., Fuentes, F., Gallego, I., Juan, M., León, D., Peñalver, P., Pérez, C., Sánchez, P., Artificial ponds in a Mediterranean region (Andalusia, southern Spain): agricultural and environmental issues. Water Environ. J. 25, 2011, 308-317.

Céréghino, R., Ruggiero, A., Marty, P., Angélibert, S., Biodiversity and distribution patterns of freshwater invertebrates in farm ponds of a south-western French agricultural landscape. Hydrobiologia 597, 2008, 43-51.

Chester, E.T., Robson, B.J., Anthropogenic refuges for freshwater biodiversity: Their ecological characteristics and management. Biol. Conserv. 166, 2013, 64-75.

Corbet, P.S., Dragonflies: Behavior and Ecology of Odonata, 1999, Comstock Publishing Associates, Ithaca, NY, USA.

Crase, B., Liedloff, A.C., Wintle, B.A., A new method for dealing with residual spatial autocorrelation in species distribution models. Ecography 35, 2012, 879-888.

Davies, B., Biggs, J., Williams, P., Whitfield, M., Nicolet, P., Sear, D., Bray, S., Maund, S., Comparative biodiversity of aquatic habitats in the European agricultural landscape. Agric. Ecosyst. Environ. 125, 2008, 1-8.

De Marco, P., Nogueira, D.S., Correa, C.C., Vieira, T.B., Silva, K.D., Pinto, N.S., Bichsel, D., Hirota, A.S.V., Vieira, R.R.S., Carneiro, F.M., de Oliveira, A.A.B., Carvalho, P., Bastos, R.P., Ilg, C., Oertli, B., Patterns in the organization of Cerrado pond biodiversity in Brazilian pasture landscapes. Hydrobiologia 723, 2014, 87-101.

Declerck, S., De Bie, T., Ercken, D., Hampel, H., Schrijvers, S., Van Wichelen, J., Gillard, V., Mandiki, R., Losson, B., Bauwens, D., Keijers, S., Vyverman, W., Goddeeris, B., De Meester, L., Brendonck, L., Martens, K., Ecological characteristic's of small farmland ponds: Associations with land use practices at multiple spatial scales. Biol. Conserv. 131, 2006, 523532.

Dolman, A.M., Rucker, J., Pick, F.R., Fastner, J., Rohrlack, T., Mischke, U., Wiedner, C., Cyanobacteria and cyanotoxins: the influence of nitrogen versus phosphorus. Plos One 2012, 7. Dormann, C.F., McPherson, J.M., Araujo, M.B., Bivand, R., Bolliger, J., Carl, G., Davies, R.G., Hirzel, A., Jetz, W., Kissling, W.D., Kuehn, I., Ohlemueller, R., Peres-Neto, P.R., Reineking, B., Schroeder, B., Schurr, F.M., Wilson, R., Methods to account for spatial autocorrelation in the analysis of species distributional data: a review. Ecography 30, 2007, 609-628. 
Dudgeon, D., Arthington, A.H., Gessner, M.O., Kawabata, Z.I., Knowler, D.J., Leveque, C., Naiman, R.J., Prieur-Richard, A.H., Soto, D., Stiassny, M.L.J., Sullivan, C.A., Freshwater biodiversity: importance, threats, status and conservation challenges. Biol. Rev. 81, 2006, 163-182.

Elith, J., Leathwick, J.R., Hastie, T., 2008. A working guide to boosted regression trees. J. Anim. Ecol. 77, 802-813.

Elphick, C.S., 2000. Functional equivalency between rice fields and seminatural wetland habitats. Conserv. Biol. 14, 181-191.

e-Stat, 2017. Portal site of official statistics of Japan. Available from http://www.e-stat.go.jp. (Accessed May 2017).

Hirai, Y., Mori, Y., Hamagami, K., Rice production environment in the rice terraces of Hoshino Village, Fukuoka Prefecture. J. Jpn. Agric. Syst. Soc. 26, 2010, 79-88 (In Japanese with English abstract).

Jeppesen, E., The Structuring Role of Submerged Macrophytes in Lakes, 1998, Springer, New York. Jeppesen, E., Jensen, J.P., Sondergaard, M., Lauridsen, T., Pedersen, L.J., Jensen, L., Top-down control in freshwater lakes: The role of nutrient state, submerged macrophytes and water depth. Hydrobiologia 342, 1997, 151-164.

Kawanabe, H., Mizuno, N., Hosoya, K.E., Freshwater Fishes of Japan, 1989, Yama-kei Publishers, Tokyo, Japan (In Japanese).

Kovalenko, K.E., Thomaz, S.M., Warfe, D.M., Habitat complexity: approaches and future directions. Hydrobiologia 685, 2012, 1-17.

Le Viol, I., Mocq, J., Julliard, R., Kerbiriou, C., The contribution of motorway stormwater retention ponds to the biodiversity of aquatic macroinvertebrates. Biol. Conserv. 142, 2009, 3163-3171.

Lundholm, J.T., Richardson, P.J., Habitat analogues for reconciliation ecology in urban and industrial environments. J. Appl. Ecol. 47, 2010, 966-975.

Marker, A.F.H., Nusch, E.A., Rai, H., Riemann, B., The measurement of photosynthetic pigments in freshwaters and standardization of methods: conclusions and recommendations. Arch. Hydrobiol. 14, 1980, 91-106.

Matsuzaki, S.S., Usio, N., Takamura, N., Washitani, I., Effects of common carp on nutrient dynamics and littoral community composition: roles of excretion and bioturbation. Fund. Appl. Limnol. 168, 2007, 27-38. 
Menetrey, N., Sager, L., Oertli, B., Lachavanne, J.B., Looking for metrics to assess the trophic state of ponds. Macroinvertebrates and amphibians. Aquat. Conserv. 15, 2005, 653-664.

Ministry of the Environment, Japan Integrated Biodiversity Information System (J-IBIS), 2000, Available from http://www.biodic.go.jp/ (accessed July 2012).

Negishi, J.N., Tamaoki, H., Watanabe, N., Nagayama, S., Kume, M., Kayaba, Y., Kawase, M., Imperiled freshwater mussels in drainage channels associated with rare agricultural landscape and diverse fish communities. Limnology 15, 2014, 237-247.

Phillips, G., Willby, N., Moss, B., Submerged macrophyte decline in shallow lakes: What have we learnt in the last forty years? Aquat. Bot. 135, 2016, 37-45.

R Development Core Team, R: A language and environment for statistical computing, 2016, R Foundation for Statistical Computing, Vienna, Austria.

Raebel, E.M., Merckx, T., Feber, R.E., Riordan, P., Thompson, D.J., Macdonald, D.W., Multi-scale effects of farmland management on dragonfly and damselfly assemblages of farmland ponds. Agric. Ecosyst. Environ. 161, 2012, 80-87.

Ridgeway, G., gbm: Generalized boosted regression models, 2016, R package Version 2.1.1.

Rodríguez, C.F., BécaresFernández-Aláez, M., Fernández-Aláez, C., Loss of diversity and degradation of wetlands as a result of introducing exotic crayfish. Biol. Invasions 7, 2005, 75-85.

Rosenzweig, M.L., Reconciliation ecology and the future of species diversity. Oryx 37, 2003, 194-205.

Rosset, V., Angelibert, S., Arthaud, F., Bornette, G., Robin, J., Wezel, A., Vallod, D., Oertli, B., Is eutrophication really a major impairment for small waterbody biodiversity? J. Appl. Ecol. 51, $2014,415-425$.

Scheffer, M., van Nes, E.H., Shallow lakes theory revisited: various alternative regimes driven by climate, nutrients, depth and lake size. Hydrobiologia 584, 2007, 455-466.

Takamura, N., Aquatic organisms and their environments in irrigation ponds, 2011, National Institute for Environmental Studies, Tsukuba, Japan (In Japanese).

Takamura, N., The status of biodiversity loss in lakes and ponds in Japan. In: Nakano, S., Yahara, T., Nakashizuka, T. (Eds.), Biodiversity Observation Network in Asia-Pacific Region: Towards Further Development of Monitoring Activities, 2012, Springer Japan, Tokyo, Japan, pp. 133148. 
Taniguchi, H., Nakano, S., Tokeshi, M., Influences of habitat complexity on the diversity and abundance of epiphytic invertebrates on plants. Freshwater Biol. 48, 2003, 718-728.

Uchii, K., Okuda, N., Yonekura, R., Karube, Z., Matsui, K., Kawabata, Z., Trophic polymorphism in bluegill sunfish (Lepomis macrochirus) introduced into Lake Biwa: evidence from stable isotope analysis. Limnology 8, 2007, 59-63.

Usio, N., Environmentally Friendly Farming in Japan: Introduction. In: Usio, N., Miyashita, T. (Eds.), Social-ecological Restoration in Paddy-dominated Landscapes, 2014, Springer Japan, Tokyo, Japan, pp. 69-86.

Usio, N., Imada, M., Akasaka, M., Takamura, N., Effects of pond management on the distributions of aquatic invaders in Japanese farm ponds. Feature Biological invasions and human activities, Jpn. J. Limnol. 70, 2009. 261-266 (In Japanese with English abstract).

Usio, N., Imada, M., Nakagawa, M., Akasaka, M., Takamura, N., Effects of pond draining on biodiversity and water quality of farm ponds. Conserv. Biol. 27, 2013, 1429-1438.

Usio, N., Saito, R., Akanuma, H., Watanabe, R., Effectiveness of wildlife-friendly farming on aquatic macroinvertebrate diversity on Sado Island in Japan. In: Usio, N., Miyashita, T. (Eds.), Socialecological Restoration in Paddy-dominated Landscapes, 2014, Springer Japan, Tokyo, Japan, pp. 95-113.

Usio, N., Saito, R., Akanuma, H., Watanabe, R., Effectiveness of wildlife-friendly farming on aquatic macroinvertebrate diversity on Sado Island in Japan. In: Usio, N., Miyashita, T. (Eds.), Socialecological Restoration in Paddy-dominated Landscapes, 2014, Springer Japan, Tokyo, Japan, pp. 95-113.

Utermöhl, H., Zur Vervollkommnung der quantitativen Phytoplankton-Methodik : mit 1 table, 1958, Schweizerbart; Stuttgart.

Vanni, M.J., Layne, C.D., Arnott, S.E., "Top-down" trophic interactions in lakes: Effects of fish on nutrient dynamics. Ecology 78, 1997, 1-20.

Wezel, A., Oertli, B., Rosset, V., Arthaud, F., Leroy, B., Smith, R., Angélibert, S., Bornette, G., Vallod, D., Robin, J., Biodiversity patterns of nutrient-rich fish ponds and implications for conservation. Limnology 15, 2014, 213-223. 
644 Williams, P., Whitfield, M., Biggs, J., Bray, S., Fox, G., Nicolet, P., Sear, D., Comparative

645 biodiversity of rivers, streams, ditches and ponds in an agricultural landscape in Southern

646 England. Biol. Conserv. 115, 2004, 329-341. 
Table 1. Summary statistics of 64 farm ponds in western Japan.

\begin{tabular}{|c|c|c|c|}
\hline Variables & Mean & SD & Range or category \\
\hline \multicolumn{4}{|l|}{ Biotic variables } \\
\hline phytoplankton (no. taxa) & 39.5 & 14.9 & $5-72$ \\
\hline aquatic plant (no. taxa) & 5.5 & 5.3 & $0-22$ \\
\hline zooplankton (no. taxa) & 20.6 & 5.2 & $9-34$ \\
\hline macroinvertebrate (no. taxa) & 19.6 & 7.7 & $6-48$ \\
\hline fish (no. taxa) & 1.5 & 1.3 & $0-4$ \\
\hline adult Odonata (no. taxa) & 14.9 & 6.2 & $4-30$ \\
\hline bluegill occurrence & NA & NA & presence, absence \\
\hline red swamp crayfish occurrence & NA & NA & presence, absence \\
\hline fish abundance (catch per unit effort) & 93.1 & 134.2 & $0-523$ \\
\hline floating-leaved macrophyte coverage (\%) & 17.9 & 30.1 & $0-94.1$ \\
\hline \multicolumn{4}{|l|}{ Water-quality variables } \\
\hline cyanobacteria $\left(\right.$ cell $\left.\mathrm{mL}^{-1}\right)$ & 11,932 & 21,180 & $0-74,379$ \\
\hline bottom dissolved oxygen $\left(\mathrm{mg} \mathrm{L}^{-1}\right)$ & 3.6 & 3.3 & $0.3-11.3$ \\
\hline chlorophyll-a $\left(\mu \mathrm{g} \mathrm{L}^{-1}\right)$ & 72.4 & 102.9 & $1-438$ \\
\hline total phosphorus $\left(\mathrm{mg} \mathrm{L}^{-1}\right)$ & 0.13 & 0.14 & $0.01-0.68$ \\
\hline total nitrogen $\left(\mathrm{mg} \mathrm{L}^{-1}\right)$ & 1.32 & 1.30 & $0.20-5.61$ \\
\hline suspended solids $\left(\mathrm{mg} \mathrm{L}^{-1}\right)$ & 20.7 & 21.6 & $1.5-127.8$ \\
\hline Secchi depth (m) & 0.7 & 0.6 & $0.1-3.6$ \\
\hline \multicolumn{4}{|l|}{ Morphometric variables } \\
\hline pond surface area (ha) & 1.10 & 1.48 & $0.08-11.43$ \\
\hline water depth (m) & 1.7 & 1.1 & $0.1-4.8$ \\
\hline \multicolumn{4}{|l|}{ Geographical variable } \\
\hline elevation (m) & 58.2 & 33.6 & $8.0-133.7$ \\
\hline \multicolumn{4}{|l|}{ Landscape variables } \\
\hline freshwater $(\%)$ & 3.8 & 3.6 & $0-18.7$ \\
\hline broadleaved forest (\%) & 25.9 & 29.4 & $0-91.9$ \\
\hline paddy field (\%) & 32.1 & 21.2 & $0-80.6$ \\
\hline cropland (\%) & 3.6 & 5.8 & $0-23.5$ \\
\hline grassland (\%) & 15.0 & 13.1 & $0-70.6$ \\
\hline urban area $(\%)$ & 19.6 & 23.2 & $0-93.0$ \\
\hline \multicolumn{4}{|l|}{ Pond management } \\
\hline concrete bank construction $(\%)$ & 44.5 & 36.4 & $0-100.0$ \\
\hline pond draining & NA & NA & $\begin{array}{l}\text { undrained, partially- } \\
\text { drained, drained }\end{array}$ \\
\hline water source & NA & NA & $\begin{array}{l}\text { agricultural drain, } \\
\text { dam, natural }\end{array}$ \\
\hline
\end{tabular}


649 Table 2. Scale-dependent effects of landscape variables on the total phosphorus concentration and 650 taxonomic richness of farm pond communities on the basis of generalised linear models. The smallest 651 Akaike's information criterion (AIC) value in each model is indicated in bold typeface.

\begin{tabular}{|c|c|c|c|c|c|c|c|}
\hline \multirow[b]{2}{*}{$\begin{array}{l}\text { Spatial } \\
\text { scale }\end{array}$} & \multirow{2}{*}{$\begin{array}{l}\text { Concentration } \\
\text { Total } \\
\text { phosphorus }\end{array}$} & \multicolumn{6}{|c|}{ Taxonomic richness } \\
\hline & & $\begin{array}{l}\text { Phyto- } \\
\text { plankton }\end{array}$ & $\begin{array}{l}\text { Aquatic } \\
\text { plant }\end{array}$ & $\begin{array}{l}\text { Zoo- } \\
\text { plankton }\end{array}$ & $\begin{array}{l}\text { Macro- } \\
\text { invertebrat } \\
\mathrm{e}\end{array}$ & Fish & $\begin{array}{l}\text { Adult } \\
\text { Odonata }\end{array}$ \\
\hline Null & 196.29 & 530.13 & 152.79 & 396.84 & 63.21 & 207.71 & -15.54 \\
\hline 10 & 167.76 & 514.33 & 157.53 & 401.27 & 60.88 & 197.38 & -24.28 \\
\hline 100 & 164.02 & 514.92 & 158.39 & 397.99 & 57.79 & 203.28 & -30.38 \\
\hline 250 & 166.22 & 519.61 & 157.46 & 393.68 & 58.28 & 204.13 & -36.35 \\
\hline 500 & 163.33 & 522.74 & 156.72 & 395.16 & 56.34 & 203.36 & -38.89 \\
\hline 1000 & 170.05 & 532.09 & 156.35 & 398.70 & 54.81 & 198.87 & -31.14 \\
\hline 2000 & 158.70 & 529.29 & 153.77 & 398.46 & 53.85 & 202.72 & -34.28 \\
\hline
\end{tabular}


Table 3. Contributions of land-use (i.e. landscape variables and modern pond management), fish abundance, and other environmental variables to the total phosphorus concentration in boosted regression-tree models. The contribution of each variable was assessed by the percentage deviance $\left(D^{2}\right)$ explained after exclusion of each variable from the simplified model. Small letters in brackets (a to f) refer to the labels. Percentage contributions of each land-use variable and fish abundance were calculated based on the formula shown in the brackets.

\begin{tabular}{|c|c|}
\hline Source & Total phosphorus concentration $\left(\mathrm{mg} \mathrm{L}^{-1}\right)$ \\
\hline Water PC1 & - \\
\hline Water PC2 & - \\
\hline Floating-leaved macrophyte coverage & 6.2 \\
\hline Aquatic plant richness & removed \\
\hline Fish abundance & 7.1 \\
\hline Bluegill occurrence & removed \\
\hline Red swamp crayfish occurrence & removed \\
\hline Pond surface area & removed \\
\hline Water depth & 23.4 \\
\hline Pond draining & removed \\
\hline Water source & 5.6 \\
\hline Concrete bank construction & 8.1 \\
\hline FRW2000 & removed \\
\hline BRF2000 & 20.6 \\
\hline PDF2000 & 11.6 \\
\hline CRO2000 & removed \\
\hline GRA2000 & 17.4 \\
\hline \multicolumn{2}{|l|}{ Percentage deviance explained } \\
\hline simplified model (a) & 59.9 \\
\hline without GRA2000 (b) & 61.0 \\
\hline without BRF2000 (c) & 58.9 \\
\hline without PDF2000 (d) & 59.6 \\
\hline without concrete bank construction (e) & 60.5 \\
\hline without fish abundance (f) & 58.3 \\
\hline$\%$ contribution of GRA2000 $(a-b)$ & -1.2 \\
\hline$\%$ contribution of BRF2000 $(\mathrm{a}-\mathrm{c})$ & 0.9 \\
\hline$\%$ contribution of PDF2000 $(\mathrm{a}-\mathrm{d})$ & 0.3 \\
\hline$\%$ contribution of concrete bank construction $(\mathrm{a}-\mathrm{e})$ & -0.7 \\
\hline$\%$ contribution of fish abundance $(\mathrm{a}-\mathrm{f})$ & 1.5 \\
\hline
\end{tabular}

659 The notation "-" indicates that the variable was not used as a predictor in the model. See text and 660 Table S1 for significant principal component loadings of water-quality variables (Water PC1-2). The 661 number in the landscape variables indicates the buffer radius used to calculate the coverage of the 662 surrounding landscape component. FRW = freshwater, BRF = broadleaved forest, PDF = paddy field, $\mathrm{CRO}=$ cropland, $\mathrm{GRA}=$ grassland. 
664 Table 4. Percentage contributions of predictors and model performance with and without Water PC1 in simplified, boosted regression-tree models.

\begin{tabular}{|c|c|c|c|c|c|c|}
\hline \multirow{2}{*}{ Source } & \multicolumn{6}{|c|}{ Taxonomic richness } \\
\hline & Phytoplankton & Aquatic plant & Zooplankton & Macroinvertebrate & Fish & Adult Odonata \\
\hline Water PC1 & 18.5 & 10.1 & removed & 19.5 & 14.6 & 9.0 \\
\hline Water PC2 & removed & 13.7 & removed & 10.3 & removed & removed \\
\hline Floating-leaved macrophyte coverage & 10.2 & 34.9 & 14.8 & removed & removed & 4.2 \\
\hline Aquatic plant richness & removed & - & removed & 20.6 & removed & 16.9 \\
\hline Fish abundance & 13.6 & removed & removed & removed & 31.5 & 7.7 \\
\hline Bluegill occurrence & removed & removed & 15.6 & removed & removed & 2.7 \\
\hline Red swamp crayfish occurrence & removed & removed & removed & removed & removed & removed \\
\hline Pond surface area & 14.5 & 10.6 & 20.2 & removed & removed & 6.6 \\
\hline Water depth & removed & 11.1 & removed & removed & 10.6 & 9.7 \\
\hline Pond draining & removed & removed & removed & removed & removed & removed \\
\hline Water source & removed & 6.5 & removed & removed & removed & removed \\
\hline Concrete bank construction & 10.4 & 13.2 & removed & 28.6 & removed & 11.3 \\
\hline FRW10 & removed & - & - & - & removed & - \\
\hline BRF10 & 26.0 & - & - & - & 24.4 & - \\
\hline PDF10 & 6.8 & - & - & - & removed & - \\
\hline CRO10 & removed & - & - & - & removed & - \\
\hline GRA10 & removed & - & - & - & removed & - \\
\hline FRW250 & - & - & 18.6 & - & - & - \\
\hline BRF250 & - & - & removed & - & - & - \\
\hline PDF250 & - & - & 30.9 & - & - & - \\
\hline $\mathrm{CRO} 250$ & - & - & removed & - & - & - \\
\hline GRA250 & - & - & removed & - & - & - \\
\hline FRW500 & - & - & - & - & - & removed \\
\hline
\end{tabular}




\begin{tabular}{|c|c|c|c|c|c|c|}
\hline \multirow{2}{*}{ Source } & \multicolumn{6}{|c|}{ Taxonomic richness } \\
\hline & Phytoplankton & Aquatic plant & Zooplankton & Macroinvertebrate & Fish & Adult Odonata \\
\hline BRF500 & - & - & - & - & - & 20.8 \\
\hline PDF500 & - & - & - & - & - & 11.2 \\
\hline CRO500 & - & - & - & - & - & removed \\
\hline GRA500 & - & - & - & - & - & removed \\
\hline FRW1000 & - & - & - & - & - & - \\
\hline BRF1000 & - & - & - & - & - & - \\
\hline PDF1000 & - & - & - & - & - & - \\
\hline CRO1000 & - & - & - & - & - & - \\
\hline GRA1000 & - & - & - & - & - & - \\
\hline FRW2000 & - & - & - & removed & - & - \\
\hline BRF2000 & - & - & - & 10.2 & - & - \\
\hline PDF2000 & - & - & - & removed & - & - \\
\hline CRO2000 & - & - & - & removed & - & - \\
\hline GRA2000 & - & - & - & 10.7 & - & - \\
\hline RAC & - & - & - & - & 18.9 & - \\
\hline \multicolumn{7}{|l|}{ Deviance explained (\%) } \\
\hline simplified model & 19.3 & 33.4 & 17.3 & 20.9 & 21.1 & 48.8 \\
\hline with water PC1 & 19.3 & 33.4 & 15.4 & 20.9 & 21.1 & 48.8 \\
\hline without water PC1 & 17.7 & 33.2 & 17.3 & 20.3 & 21.7 & 48.8 \\
\hline$\%$ contribution of water $\mathrm{PC} 1$ & 1.6 & 0.2 & - & 0.7 & -0.6 & 0 \\
\hline
\end{tabular}

665 The notation "-" indicates that the variable was not used as a predictor in the model. The notation "removed" indicates that the variable was removed 666 from the simplified model. See text and Table S1 for significant principal component loadings of water-quality variables (Water PC1-2). FRW = 667 freshwater, $\mathrm{BRF}=$ broadleaved forest, $\mathrm{PDF}=$ paddy field, $\mathrm{CRO}=$ cropland, $\mathrm{GRA}=$ grassland, $\mathrm{RAC}=$ residual autocovariate. 


\section{Figure legends}

Figure 1. Map of the 64 farm ponds in Hyogo Prefecture, Japan.

Figure 2. Taxonomic richness of six biological indicators of 64 farm ponds in western Japan. The main taxonomic resolutions are species for aquatic plants, phytoplankton, zooplankton, fish, and adult Odonata, and genus for macroinvertebrates. The thick lines show the medians, and the boxes delineate the interquartile ranges. The whiskers denote 1.5 times the interquartile range. Small circles above the whiskers indicate outliers.

Figure 3. Partial plots of the effects of land-use variables (landscape variables and modern pond management), fish abundance, and other environmental variables on the total phosphorus concentration in the simplified, boosted regression-tree model. The fitted function represents the effects of the selected variable on the response variable. Relative contributions of predictor variables are shown in parentheses. Rug plots inside the top of each plot show the distribution of sites across the variable in deciles. The number in the landscape variables indicates the buffer radius used to calculate the coverage of the surrounding landscape component. $\mathrm{BRF}=$ broadleaved forests, $\mathrm{GRA}=$ grassland, $\mathrm{PAD}=$ paddy field, $\mathrm{CPUE}=$ catch per unit effort.

Figure 4. Partial plots of the effects of Water PC1 (the first principal component axis from a principal component analysis (PCA) of seven water-quality variables; see text) on taxonomic richness of five biological indicators in the simplified, boosted regression-tree models. The fitted function represents the effects of the selected variable on the response variable. The relative contributions of predictor variables are shown in parentheses. Rug plots inside the top of each plot show the distribution of sites across the variable in deciles.

Figure 5. Conceptual model summarising the results of the study. Thick arrows indicate strong effects (not to scale). 


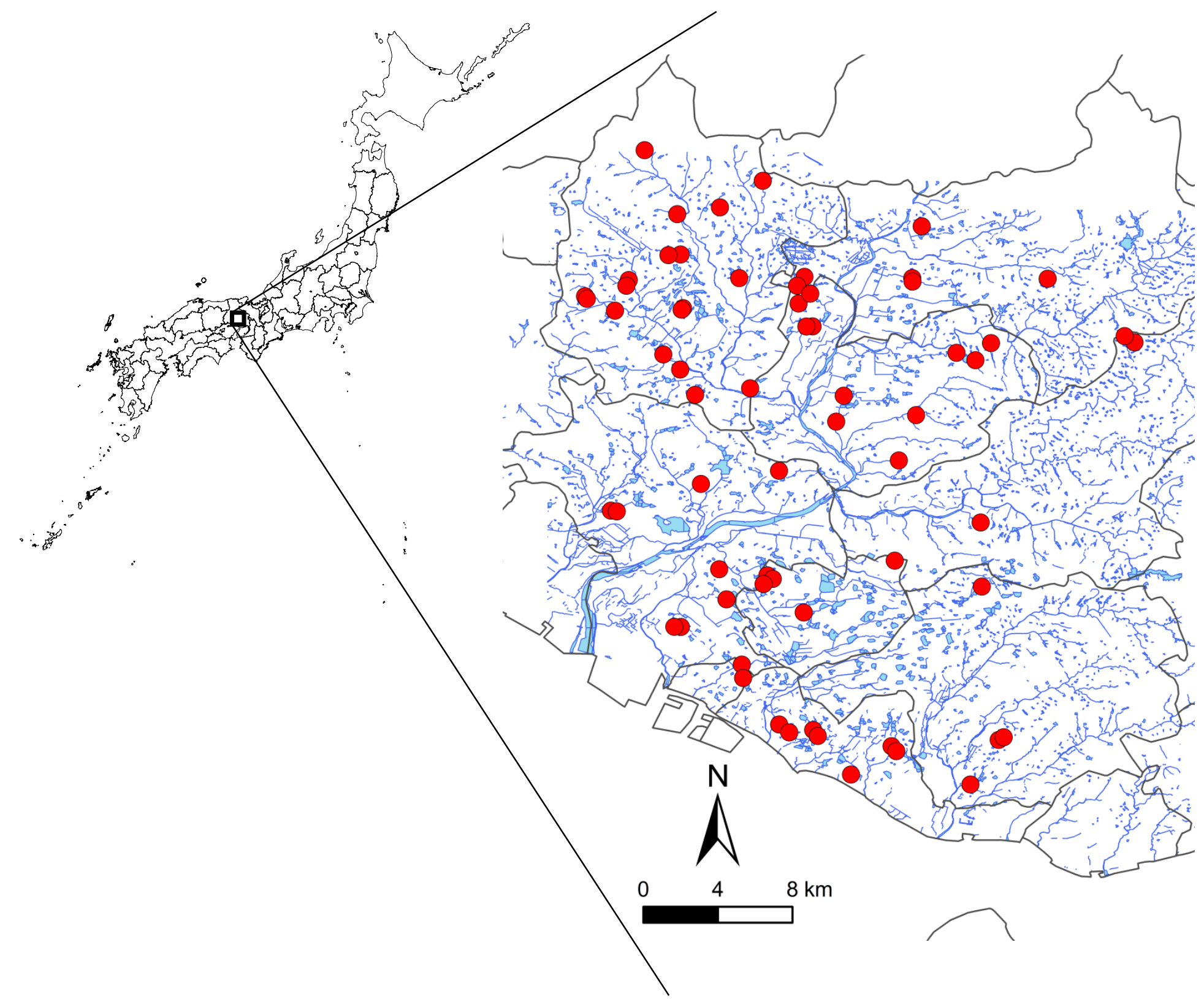

Fig. 1 Usio et al. 


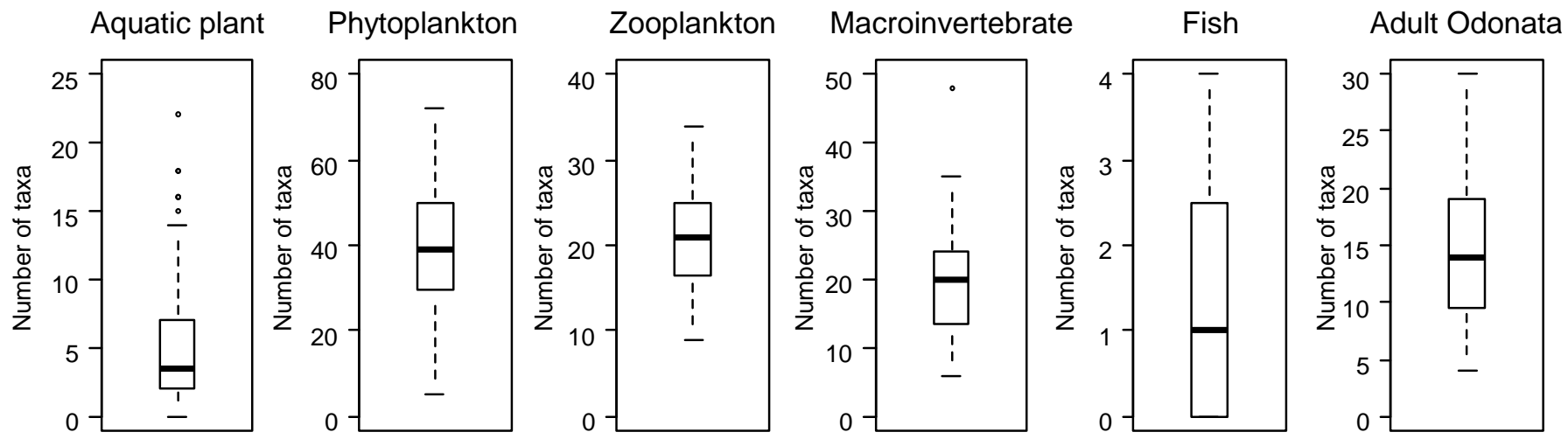

Fig. 2 Usio et al. 


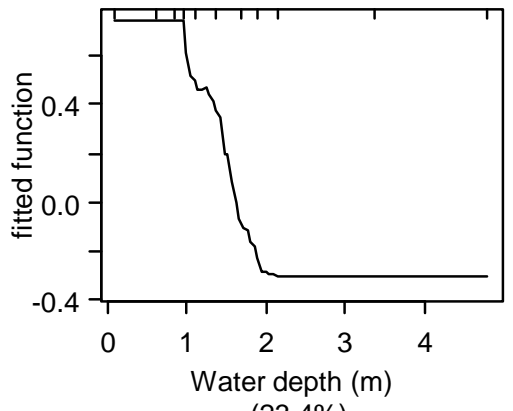

(23.4\%)

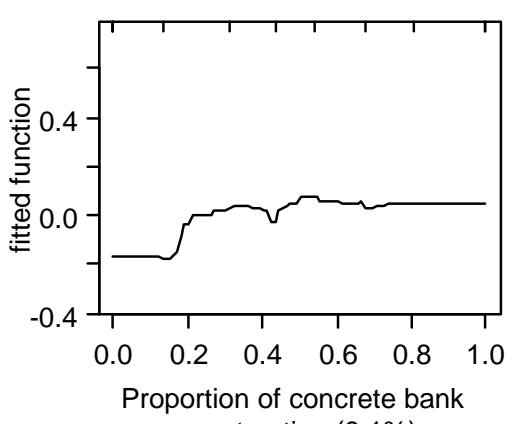

construction (8.1\%)
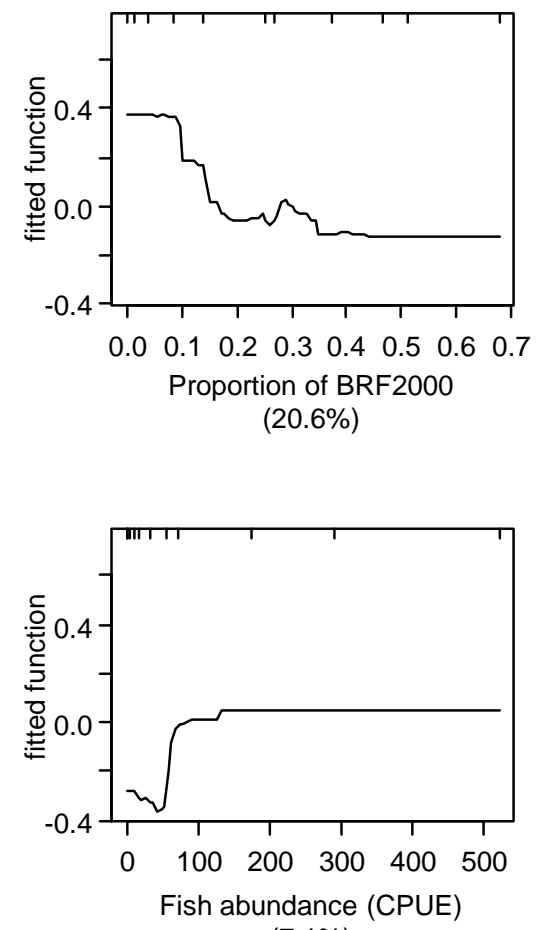

(7.1\%)

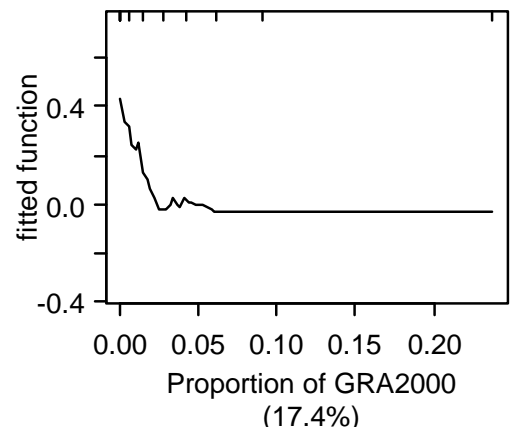

(17.4\%)

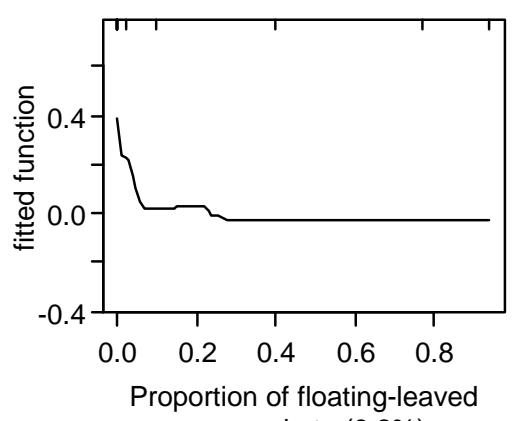

macrophyte (6.2\%)

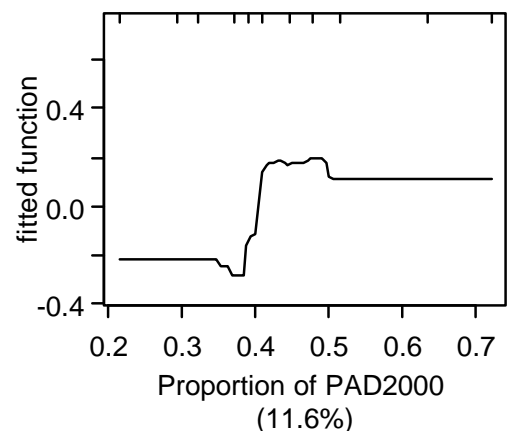

(11.6\%)

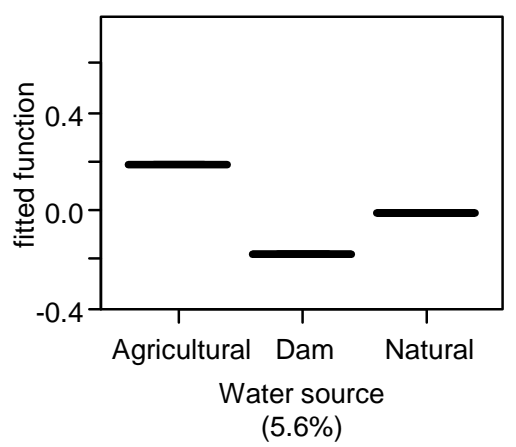

(5.6\%)

Fig. 3 Usio et al. 
Phytoplankton

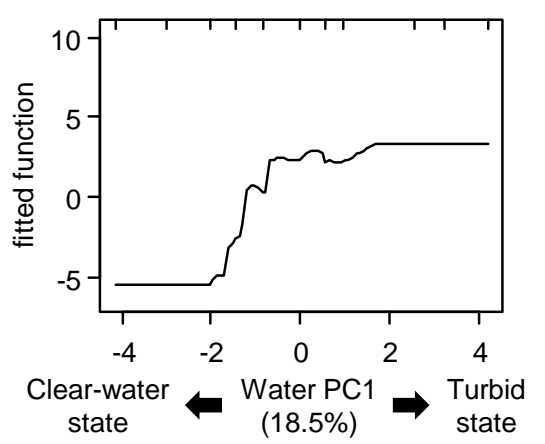

Aquatic plant

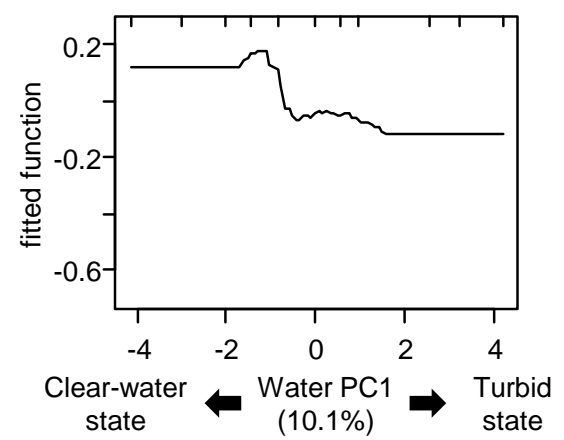

Fish

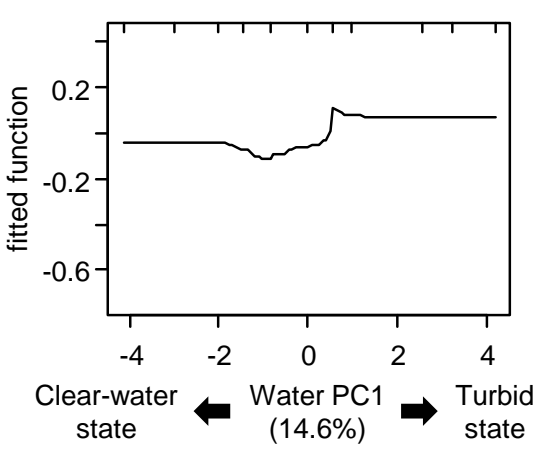

Adult Odonata

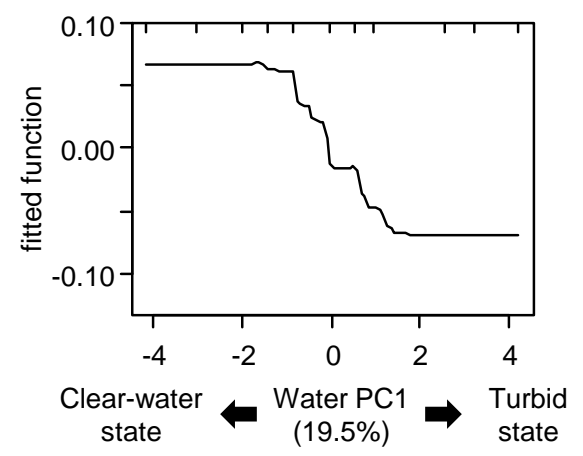

Macroinvertebrate

ate state

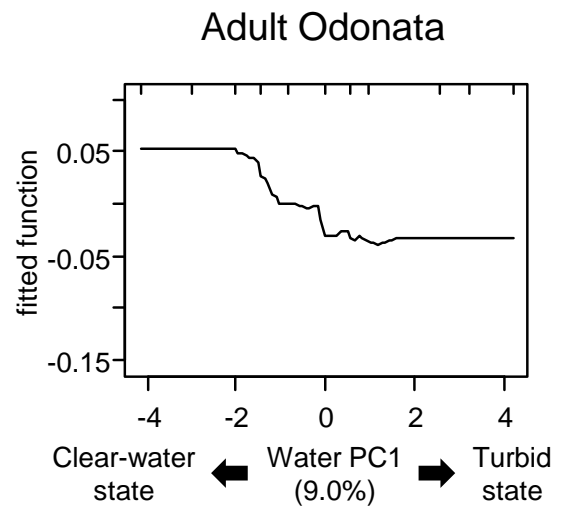

Fig. 4 Usio et al. 


\section{Stressor}

- Landscape factors

- Modern pond management

Driver of trophic state change

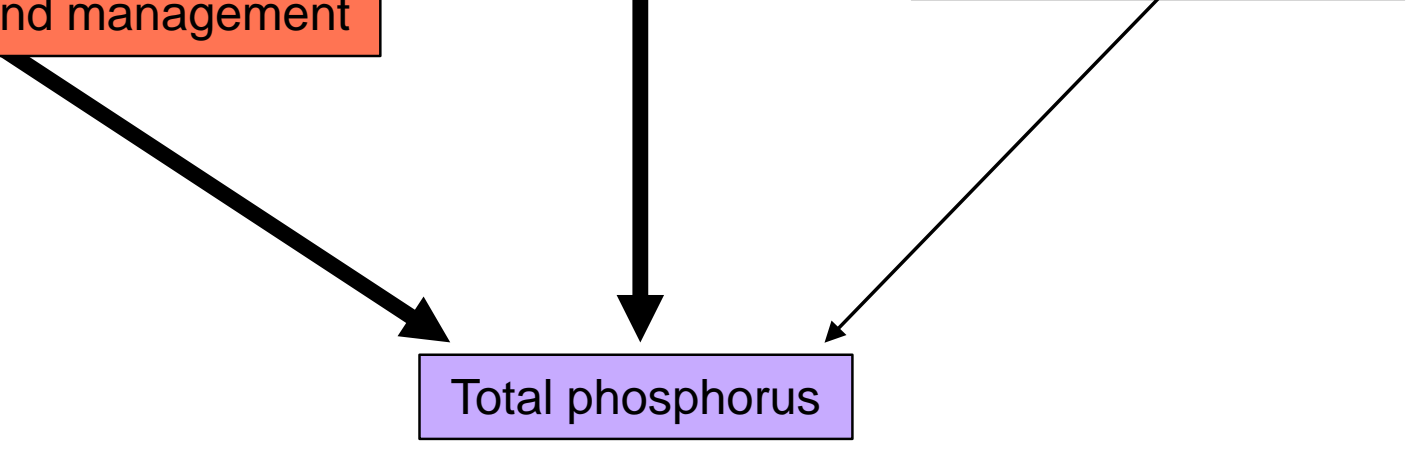

Driver of multi-taxonomic diversity change

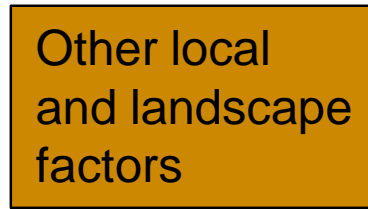

\section{\begin{tabular}{|l|l|}
\hline Fish abundance $\quad$ Other environmental \\
\hline
\end{tabular}} factors

\section{factors}

Fig. 5 Usio et al. 


\section{Supplementary materials}

Table S1. Loadings of the first two principal component axes for water-quality variables in the principal component analysis (PCA).

\begin{tabular}{lrr}
\hline Water quality & Water PC1 & Water PC2 \\
\hline chlorophyll-a $\left(\mu \mathrm{g} \mathrm{L}^{-1}\right)$ & 0.416 & -0.165 \\
total phosphorus $\left(\mathrm{mg} \mathrm{L}^{-1}\right)$ & 0.411 & -0.106 \\
total nitrogen $\left(\mathrm{mg} \mathrm{L}^{-1}\right)$ & 0.404 & -0.129 \\
cyanobacteria $\left(\mathrm{cells} \mathrm{mL}^{-1}\right)$ & 0.411 & -0.020 \\
suspended solids $\left(\mathrm{mg} \mathrm{L}^{-1}\right)$ & 0.410 & 0.128 \\
bottom dissolved oxygen $\left(\mathrm{mg} \mathrm{L}^{-1}\right)$ & 0.049 & 0.945 \\
Secchi depth (m) & -0.394 & -0.186 \\
\hline eigenvalue & 5.164 & 1.065 \\
proportion of variance explained & 0.738 & 0.152 \\
cumulative proportion & 0.738 & 0.890 \\
\hline
\end{tabular}



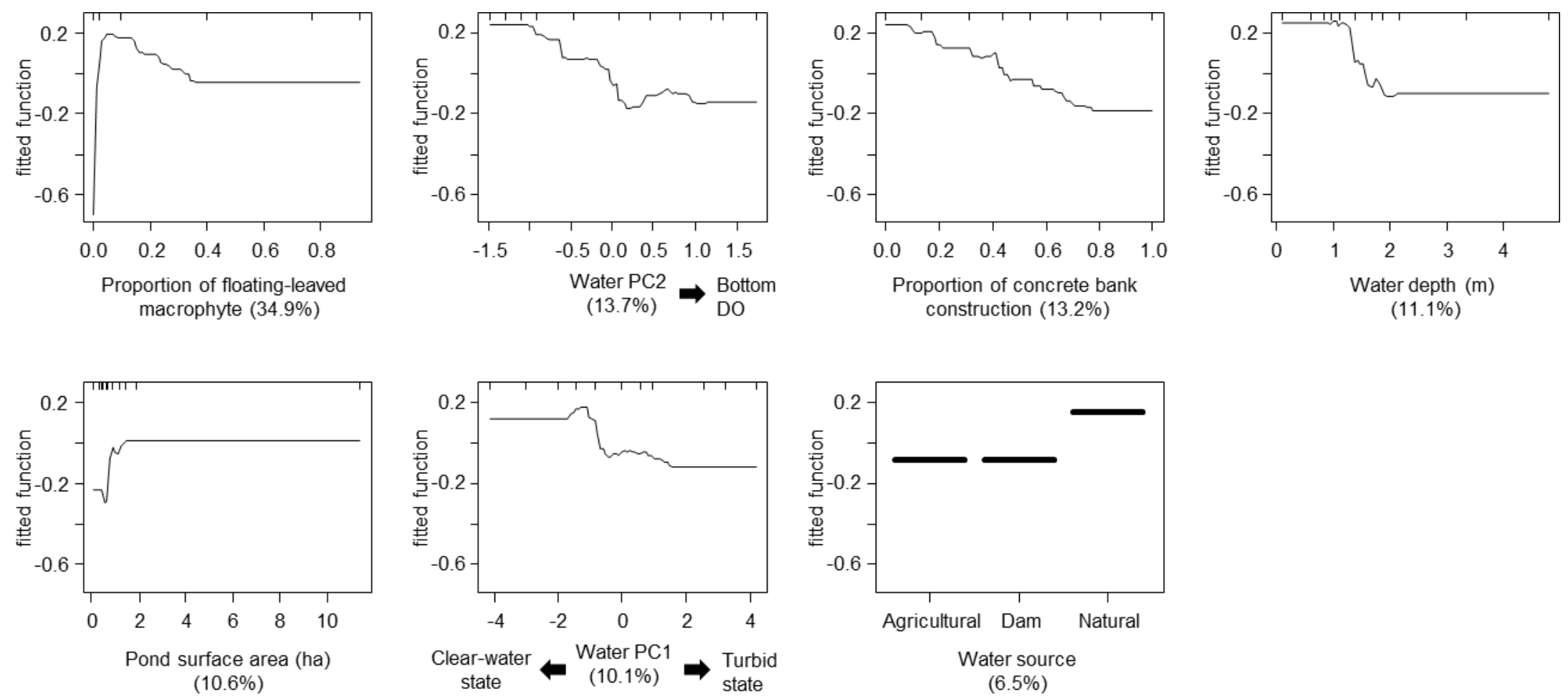

Figure S1. Partial plots of the effects of land-use (concrete bank construction) and other environmental variables on the taxonomic richness of aquatic plants in the simplified, boosted regression-tree model. The fitted function represents the effects of the selected variable on the response variable. Relative contributions of predictor variables are shown in parentheses. Rug plots inside the top of each plot show the distribution of sites across the variable in deciles. Water PC1 and Water PC2 refer to the first and second principal component axes from a principal component analysis (PCA) of seven water quality variables (see text and Table S1). Bottom DO = bottom dissolved oxygen. 